\title{
Histomorphological study of lesions of corpus uteri in hysterectomy specimens: a tertiary care centre study
}

\author{
Patil T. ${ }^{1}$, Kulkarni M.A. ${ }^{2}$, Anand A.S. ${ }^{3}$, Punyashetty K.B. ${ }^{4}$ \\ ${ }^{1}$ Dr. Tejeshwini Patil, Assistant Professor, Department of Pathology, Raichur Institute of Medical Sciences, Raichur, \\ Karnataka, India, ${ }^{2}$ Dr. Madhavi A. Kulkarni, Assistant Professor, ${ }^{3}$ Dr. A. S. Anand, Professor and HOD, ${ }^{4}$ Dr. Kajal B. \\ Punyashetty, Professor; ${ }^{2,3,4}$ authors are affiliated with Department of Pathology, Navodaya Medical College, Hospital and \\ Research Centre, Raichur, Karnataka, India.
}

Corresponding Author: Dr. Madhavi A. Kulkarni, Assistant Professor, Department of Pathology, Navodaya Medical College, Hospital and Research Centre, Raichur, Karnataka, India. E-mail: madhavitop@yahoo.co.in

\begin{abstract}
Background: Hysterectomy is the most common surgery performed in gynaecological practice, sometimes considered a lifesaving procedure in women, which also improves the quality of life for women with certain uterine pathologies such as fibroids, endometriosis, uterine prolapse and various types of cancer. The diagnostic value of histopathological examination is well explained and enables determination of origin of a particular benign or malignant lesion and in the latter, where adjuvant treatment is dependent upon grade and extent of invasion of disease. Aims: To study the histomorphological spectrum of lesions of corpus uteri in hysterectomy specimens and their distribution in different age groups along with clinicopathological correlation. Materials and Methods: The present study comprised of 450 hysterectomy specimens with lesions in the corpus uteri, received in the Department of Pathology, Navodaya Medical College, Raichur, during 5 years from October 2012 to September 2017. All the specimens were subjected to histomorphological study and clinical correlation was made. Results: The commonest type of hysterectomy was abdominal hysterectomy (84\%) with the peak age incidence in 5th decade (45.33\%). Most common clinical diagnosis was fibroid uterus (45.55\%) and pathological diagnosis was leiomyoma (59.33\%) and malignancy being endometrial carcinoma (2.67\%). Clinicopathological correlation was observed in $46 \%$ of cases, commonly among malignant lesions $(87.5 \%)$, when compared to benign lesions of corpus uteri (65.16\%). Conclusion: The study emphasizes on histomorphological evaluation of lesions in hysterectomy specimens and is mandatory as various benign and malignant conditions occur with increasing frequency and carries diagnostic and therapeutic significance and should be done in all cases for confirming the preoperative clinical diagnosis and thus ensuring a better postoperative outcome.
\end{abstract}

Keywords: Endometrial carcinoma; Hysterectomy; Histomorphology; Leiomyoma; Uterus.

\section{Introduction}

The female genital tract is a hormone responsive system, has been affected by various abnormalities and diseases, been the object of fascination and forms the basis for one of the oldest medical specialities. Cyclic uterine bleeding which begins in the anatomically and physiologically normal female, marks an important stage of reproductive maturation [1].

The corpus uteri include the endometrium and myometrium, which is stimulated continually by hormones, denuded monthly of its endometrial mucosa, inhabited periodically by fetus and is subjected to a plethora of disorders [1]. Varied changes that occur in

Manuscript received: $14^{\text {th }}$ August 2019

Reviewed: $24^{\text {th }}$ August 2019

Author Corrected: $30^{\text {th }}$ August 2019

Accepted for Publication: $4^{\text {th }}$ September 2019 endometrium reflect its responsiveness to either hormonal stimulation of circulating estrogen and progesterone levels, or lack of it. Two cardinal clinical manifestations of gynaecological disease are abnormal uterine bleeding and infertility.

The clinical differential diagnoses of abnormal uterine bleeding provide a framework for detailed discussion and correlation of endocrinologic disturbance with uterine morphology [1].Menorrhagia, usually associated with benign lesions like uterine adenomyosis, leiomyomata and pelvic infection, is a common and debilitating problem and is a leading cause of hospitalization for gynaecological disorders all over the world. Rarely, it is secondary to malignant pathology like endometrial carcinoma [2]. Prevalence of uterine and 
Original Research Article

adnexal pathologies are varied and the lesions that afflict the uterine corpus constitute bulk of gynaecological pathologies like hyperplasias, polyps, adenomyosis, fibroids, endometriosis, inflammatory lesions like PID and neoplastic proliferations, etc [1].

Hysterectomy is a successful surgery in terms of symptom relief and patient satisfaction. It provides definitive cure to many diseases involving uterus as well as adnexae. Since early $20^{\text {th }}$ century, it is the most commonly performed gynaecological surgery throughout the world [3]. It produces an intact uterus and consequent control over tissue sampling and hence enabling determination of origin of a particular lesion [4].

Histopathological examination of hysterectomy specimens carries diagnostic and therapeutic significance and is well explained in patients with various conditions ranging from benign lesions to genital malignancy [5].

This study was conducted with a view to get insight into the varied patterns of lesions of corpus uteri in hysterectomy specimens in our institution.

\section{Materials and Methods}

Place and type of study- Prospective study constituting the histomorphological study of lesions of corpus uteri in 450 hysterectomies, along with clinicopathological correlation, irrespective of clinical indication and type of hysterectomy from October 2012 to September 2017. The hysterectomy specimens from OBG department and those from various referral centers were received in department of pathology, Navodaya Medical College, Hospital and Research Centre, Raichur.

Sampling methods and sample collection- Clinical details of the patients were obtained in consultation with the gynecologist and entry was made in the proforma. The specimens were immediately fixed in $10 \%$ fresh formalin in the ratio of 1:10 by volume. After 24 hours fixation, the specimen was examined grossly and described as per the set standards. After formalin fixation, multiple bits were taken from representative sites, processed and paraffin blocks were made. The blocks were cut at $3-5 \mu \mathrm{m}$ thickness and stained with Hematoxylin and Eosin. Special stains such as PAS and Alcian Blue were used wherever necessary.

Inclusion criteria: All the lesions of corpus uteri in hysterectomy specimens received in department of Pathology were included in the study.

Exclusion criteria: Lesions of cervix and gestational diseases of uterus were excluded from the study.

The histomorphological study of corpus uteri was done systematically and the histological findings were correlated with the clinical findings.

\section{Results}

A total of 680 hysterectomy specimens were retrieved during the period October 2012 to September 2017, at the department of pathology, Navodaya Medical College Hospital and Research Centre Raichur, The study included 450 hysterectomy specimens by applying inclusion and exclusion criteria mentioned above. Out of 450 cases, abdominal hysterectomies were more frequent ( 380 cases; $84 \%$ ) than vaginal hysterectomies ( 70 cases; $16 \%$ ). The age distribution of hysterectomies ranged from 21-70 years with a mean age of 42.15 years. The youngest patient in the study was 28 years and the oldest was 66 years of age and the maximum number of cases were noted in the $5^{\text {th }}$ decade (204 cases; $45.33 \%$ ) [Table 1].

Table-1: Age distribution of cases presenting with lesions in corpus uteri

\begin{tabular}{|c|c|c|c|}
\hline Sl. No. & Age in years & No. of Cases & Percentage (\%) \\
\hline 1. & $21-30$ & 36 & 8 \\
\hline 2. & $31-40$ & 165 & 36.67 \\
\hline 3. & $41-50$ & 204 & 45.33 \\
\hline 4. & $51-60$ & 42 & 9.33 \\
\hline 5. & $61-70$ & 03 & 0.67 \\
\hline \multicolumn{2}{|c|}{ Total } & $\mathbf{4 5 0}$ & $\mathbf{1 0 0}$ \\
\hline
\end{tabular}

The most common clinical indication for hysterectomy was fibroid uterus (205 cases; $45.55 \%$ ) followed by DUB (111 cases; 24.67\%). Other indications included PID, UV prolapse, polyp and malignancy [Table 2].

Table-2: Clinical indications for hysterectomy. 
Original Research Article

\begin{tabular}{|c|c|c|c|}
\hline Sl. No. & Clinical diagnosis & No. of cases & Percentage (\%) \\
\hline 1. & Fibroid Uterus & 205 & 45.55 \\
\hline 2. & DUB & 111 & 24.67 \\
\hline 3. & PID & 48 & 10.66 \\
\hline 4. & UV Prolapse & 42 & 9.33 \\
\hline 5. & Polyp & 21 & 4.68 \\
\hline 6. & No diagnosis & 09 & 2.0 \\
\hline 7. & Ca Uterus & 14 & 3.11 \\
\hline \multicolumn{2}{|c|}{ Total } & $\mathbf{4 5 0}$ & $\mathbf{1 0 0}$ \\
\hline
\end{tabular}

The most common histopathological diagnosis was leiomyoma (267 cases; $59.33 \%$ ) followed by adenomyosis (135 cases; $30 \%$ ) and malignancy included adenocarcinoma of endometrium (12 cases; $2.67 \%$ ), MMMT ( 2 case; $0.44 \%$ ), low grade leiomyosarcoma ( 2 case; $0.44 \%$ ) and a rare case of bicornuate uterus ( 1 case; $0.22 \%$ )[Table 3$]$.

Table-3: Histopathological spectrum of lesions in hysterectomy specimens

\begin{tabular}{|c|l|c|c|}
\hline SL. No. & Histopathological diagnosis & No. of cases & Percentage (\%) \\
\hline 1. & Chronic endometritis & 9 & 2 \\
\hline 2. & Endometrial polyp & 33 & 7.33 \\
\hline 3. & Endometrial polyp; Leiomyoma & 8 & 1.8 \\
\hline 4. & Simple endometrial hyperplasia & 20 & 4 \\
\hline 5. & Complex atypical hyperplasia & 3 & 0.7 \\
\hline 6. & CGH; Leiomyoma; Adenomyosis & 3 & 0.7 \\
\hline 7. & Endometrial adenocarcinoma & 12 & 2.7 \\
\hline 8. & MMMT & 2 & 0.44 \\
\hline 9. & Adenomyosis & 90 & 20 \\
\hline 10. & Leiomyoma & 204 & 45.33 \\
\hline 11. & Leiomyoma; Adenomyosis & 42 & 9.33 \\
\hline 12. & Leiomyomatous polyp & 12 & 2.7 \\
\hline 13. & Leiomyoma; Leiomyomatous polyp & 2 & 2 \\
\hline 14. & Low grade leiomyosarcoma & 1 & 0.44 \\
\hline 15. & Bicornuate uterus with intramural leiomyoma & $\mathbf{4 5 0}$ & 0.22 \\
\hline \multicolumn{2}{r}{ Total } & & $\mathbf{1 0 0}$ \\
\hline
\end{tabular}

\section{Histomorphological features of all the lesions}

A. Chronic endometritis: Grossly, 9 cases presented with normal sized uteri. Microscopically, all these cases were of chronic endometritis and showed plasma cells, increased lymphocytes or lymphoid aggregates present in the endometrial stroma as well as neutrophils in the surface endometrium and gland lumina.

B. Endometrial polyp: Grossly, 38 cases showed bulky uteri and the other 24 were normal sized uteri. On cut section, all uteri showed polypoidal growth in endometrial cavity. Microscopically, of the 41 cases of endometrial polyp, 8 cases (19.51\%) were associated with leiomyoma. leiomyomatous polyp was seen in 12 cases and mixed with leiomyoma in 9 cases.

C. Endometrial hyperplasia: Grossly, 16 cases showed bulky uteri and 3 cases showed intramural fibroid and the other 7 were normal sized uteri. Microscopically, of the 26 cases of endometrial hyperplasia, simple endometrial hyperplasia without atypia (20 cases; $76.9 \%$ ) showed increased gland to stromal ratio and cystically dilated glands and complex atypical hyperplasia (3 cases; 11.5\%) showed irregular crowding of glands with back to back arrangement showing features of nuclear atypia. 3 case of $\mathrm{CGH}(11.5 \%)$ was associated with adenomyosis and intramural leiomyoma.

A. Endometrial carcinoma: Grossly, 12 cases of carcinoma endometrium presented with polypoidal growth (6 cases; $50 \%$ ) and infiltrative (6 cases; 50\%) [Figure 1 (A)]

Microscopic examination of cases of endometrial carcinoma revealed- 


\section{Original Research Article}

Well differentiated adenocarcinoma of endometrium (6 cases; 50\%) showed extensive, complex epithelial growth pattern with little intervening stroma and branching of large glands causing papillary structure with mild to moderate atypia infiltrating myometrium [Figure $1(\mathrm{~B})]$.

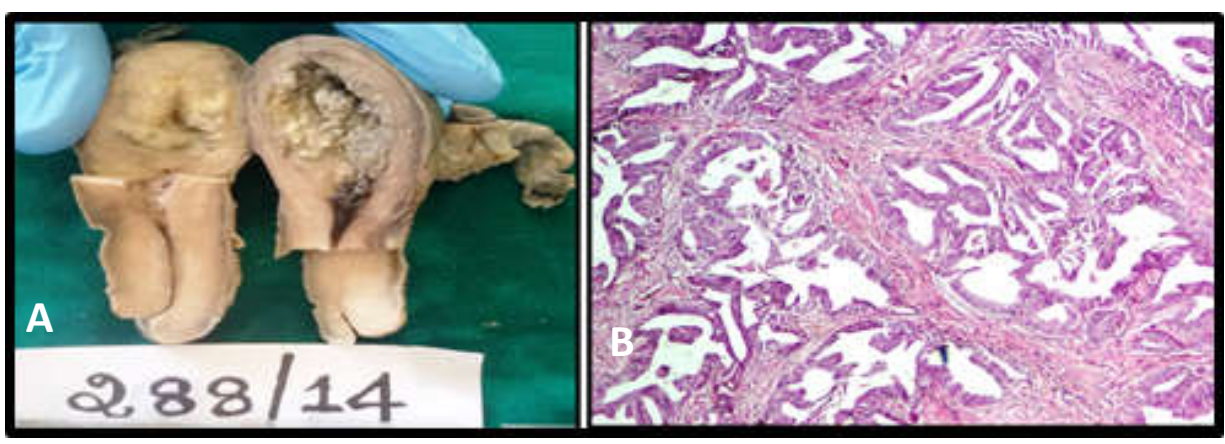

Figure 1- Gross: Endometrial carcinoma (A)- Shows diffuse infiltrating growth in endometrial cavity involving body and fundus and Microscopy: Endometrial carcinoma (B)-Well differentiated showing malignant glands (H \& E, 40 X)

Poorly differentiated adenocarcinoma (3 cases; 25\%) showed sheets of tumor cells and poorly formed glands with high grade nuclear features.

Endometriod adenocarcinoma of endometrium ( 3 cases; $25 \%$ ) showing back to back endometrial type glands of varying differentiation/atypia with no intervening stroma and a villoglandular pattern were diagnosed.

B. Mixed malignant mullerian tumour: 2 rare cases $(0.44 \%)$ of MMMT, clinically diagnosed as carcinoma uterus in $6^{\text {th }}$ decade was encountered which presented grossly as large polypoidal growth in endometrial canal extending into cervical Os. Areas of necrosis and hemorrhage were seen. Microscopically, uterus with tumor tissue composed of glandular and stromal sarcomatous components was noted. Glandular component was lined by atypical cells with pleomorphic nuclei and atypical mitosis (poorly differentiated endometrial adenocarcinoma). Stromal sarcomatous component consisted of round to spindled cells having deep eosinophilic cytoplasm with pleomorphic nuclei (Low grade ESS). Extensive areas of necrosis were seen along with atypical mitoses and tumour giant cells (rhabdomyosarcoma-heterologous element). Tumor was seen infiltrating myometrium and into the cervix.

C. Adenomyosis: Grossly, of 135 cases, 83 cases were bulky uteri with thickened and trabeculated myometrium showing cystic and hemorrhagic areas, 42 showed fibroids, 7 were unremarkable and 3 were with thickened endometrium. The thickness of myometrium ranged from $1-5 \mathrm{~cm}$. Microscopically, endometrial stroma and glands were seen deep in myometrium, one low power field from endomyometrial junction.

D. Leiomyoma: Grossly, of the 267 cases of leiomyoma, 167 uteri were bulky, 48 were normal sized, 6 were atrophic and about 46 uteri were grossly distorted. Cut surface of all the cases of leiomyoma showed whorled appearance [Figure 2 (A) and (B)]
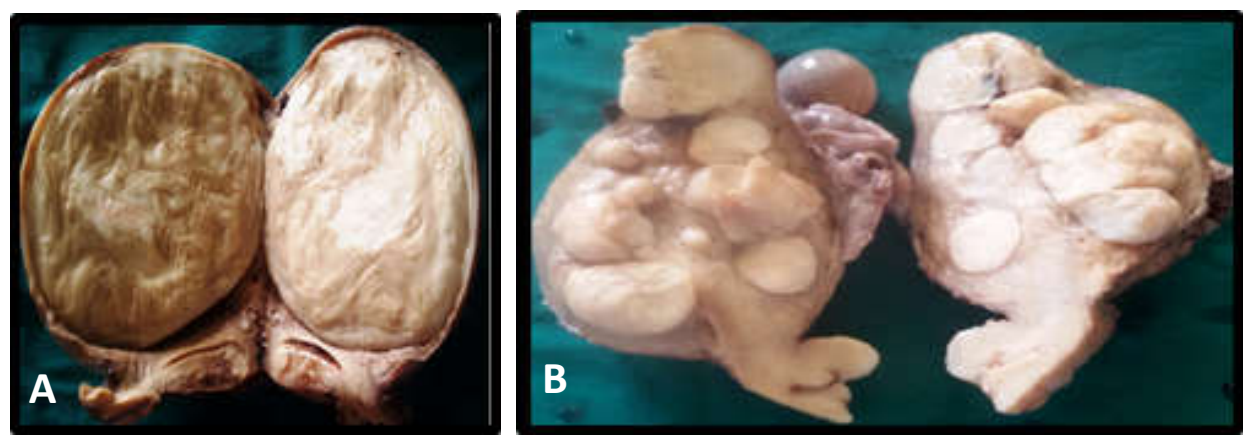

Figure 2- Gross: Intramural leiomyoma (A)- Shows large intramural grey white whorled area and Multiple leiomyomata (B) Shows intramural, submucosal and serosal location of multiple leiomyomata.

Microscopically all cases of leiomyoma showed interlacing bundles of smooth muscle cells with variable amounts of collagen [Figure $3(\mathrm{~A})$ ].

Pathology Update: Tropical Journal of Pathology \& Microbiology Available online at: www.medresearch.in 687 | P a g e 


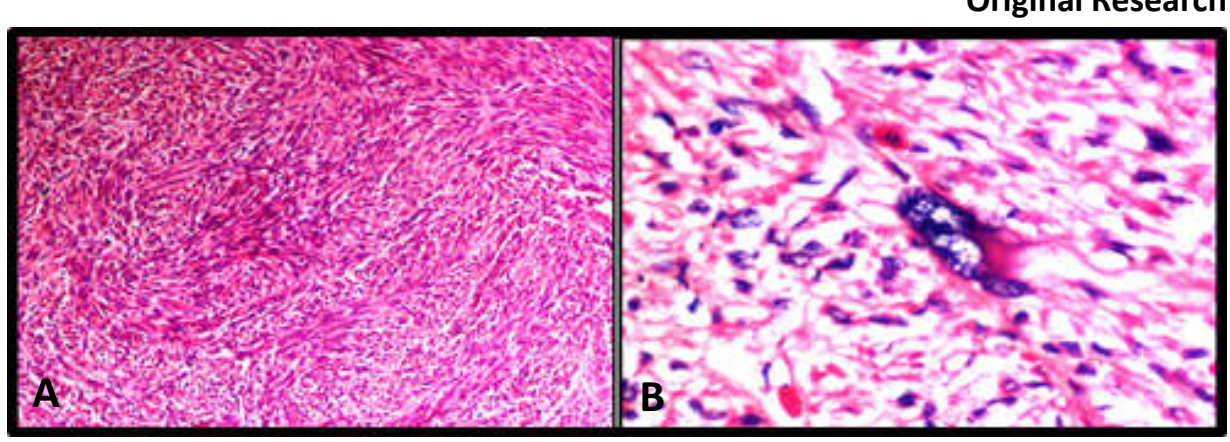

Figure 3 Microscopy: Leiomyoma (A)- Shows interlacing bundles of smooth muscle cells separated by variable quantities of collagen (H \& E, 100 X). Bizzare/ Symplastic Leiomyoma (B)- Shows bizarre atypical cells with multinucleate giant cell (H \& E, $400 \mathrm{X})$.

Among 267 cases, leiomyoma was associated with adenomyosis (42 cases; $15.77 \%$ ) endometrial polyps ( 8 cases; $2.99 \%$ ), adenomyosis and CGH (3 cases; 1.12\%). Intramural leiomyomas were the commonest (182 cases; 68.16\%), followed by mixed (44 cases; $16.49 \%$ ) [Table 4].

Table-4: Distribution of leiomyomas according to the location.

\begin{tabular}{|c|l|c|c|}
\hline Sl. No. & Location of leiomyoma & No. of Cases & Percentage (\%) \\
\hline 1. & Submucosal & 18 & 6.74 \\
\hline 2. & Intramural & 182 & 68.16 \\
\hline 3. & Subserosal & 23 & 8.61 \\
\hline 4. & Mixed & 44 & 16.49 \\
\hline \multicolumn{2}{|c|}{ Total } & $\mathbf{2 6 7}$ & $\mathbf{1 0 0}$ \\
\hline
\end{tabular}

a. Variants of leiomyoma: Of the 267 cases of leiomyoma, 9 cases $(3.37 \%)$ were variants such as cellular leiomyoma ( 8 cases; 88.89) and symplastic leiomyoma. Microscopically, cellular leiomyoma showed densely cellular areas with interlacing fascicles of smooth muscle bundles. Whereas, symplastic leiomyoma showed pleomorphic cells bordered by spindle shaped cells admixed with multinucleated giant cells with no abnormal mitosis [Figure 2 (B)].

a. Degenerative changes in leiomyoma: Of the 267 cases of leiomyoma, 37 cases $(13.85 \%)$ showed degenerative changes such as hyaline change (29 cases; $78.37 \%$ ), cystic degeneration ( 3 cases; $8.10 \%$ ) calcification ( 3 cases; $8.10 \%)$ and red degeneration (3 cases; $8.10 \%$ ).

H. Leiomyosarcoma: In the present study, leiomyosarcoma was diagnosed in 2 cases $(0.44 \%)$ with menstrual disturbances and mass per abdomen and was clinically diagnosed as fibroid uterus. Grossly, uteri were enlarged in size with irregular mass in myometrium [Figure 4 (A)]. Cut section was grey white with irregular margins and areas of hemorrhage and necrosis were evident. Microscopically, tumor tissue was hypercellular with spindle to oval cells arranged in fascicles. Nuclei were fusiform, hyperchromatic to vesicular and atypical with eosinophilic cytoplasm. Moderate to severe cellular atypia with 4-5 MFs/10 HPF along with areas of hemorrhage, mixed inflammatory infiltrate and coagulative tumor cell necrosis were noted [Figure 4(B)].

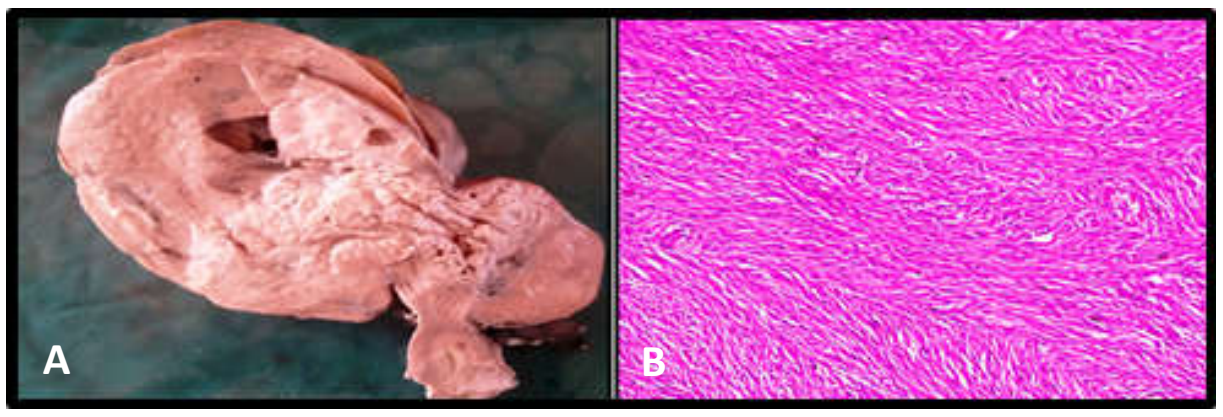

Figure 4- Gross: Low Grade Leiomyosarcoma (A): Shows a large myometrial growth with areas of hemorrhage and necrosis and Microscopy (B): Hypercellular with nuclear atypia, pleomorphism, mitotically active (H \& E, 100 X). 


\section{Original Research Article}

E. Bicornuate uterus: In the present study, a rare and interesting case $(0.22 \%)$ of bicornuate uterus was seen in 39 -yearold patient who presented with menorrhagia \& was clinically diagnosed as AUB. Grossly 2 cornua were seen, cut section of one of the cornua showed intramural fibroid which measured $2 \mathrm{~cm}$ in diameter. Microscopically, one of the cornua revealed endometrium in proliferative phase and myometrium showed intramural leiomyoma and other cornua showed atrophic endometrium and unremarkable myometrium.

Clinicopathological correlation: In the present study, 207 cases (46\%) of clinical diagnosis of lesions of corpus uteri matched with histopathological outcome, which included uterine leiomyoma (174 cases; $84.05 \%$ ), polyp (18 cases; $8.69 \%)$ and malignancy (14 cases; $5.8 \%)$.

The clinical diagnosis which had good correlation with histopathology was maximum for malignancy (14/16 cases; $87.5 \%)$ followed by fibroid uterus (174/267 cases; $65.16 \%)$.

Cases diagnosed clinically as fibroid uterus were 205 in number which were subsequently diagnosed on histopathology as leiomyoma (174 cases; $86.34 \%$ ), adenomyosis ( 24 cases), simple hyperplasia (3 cases), complex atypical hyperplasia (2 cases) and leiomyosarcoma ( 2 cases). A diagnosis of DUB was offered in 111 cases clinically and on histopathology were pathologically proven as follows - adenomyosis (39 cases), leiomyoma (39 cases), simple hyperplasia (18 cases), endometrial polyp (14 cases) and bicornuate uterus (1 case).

Clinically diagnosed cases of PID (48 cases) were histopathlogically diagnosed as endometritis ( 3 cases), leiomyoma (24 cases) and adenomyosis (21 cases). The cases diagnosed clinically as UV prolapse (42 cases) were diagnosed as leiomyoma (30 cases), endometrial polyp (9 cases) and adenomyosis ( 3 cases), histopathologically. Clinical diagnosis of polyp was done in 21 cases which were diagnosed as polyp (18 cases) and adenomyosis ( 3 cases) histopathologically.

Diagnosis of 9 cases in this study was not offered clinically, which constituted adenomyosis (6 cases) and endometritis (3 cases) and were diagnosed histopathologically. Patients diagnosed clinically as carcinoma of uterus (14 cases), correlated with histopathological diagnosis of malignancy and were endometrial adenocarcinoma (12 cases) and MMMT (2 cases), respectively.

\section{Discussion}

The history of knowledge of the uterine corpus is as interesting as ever. Hippocrates (460-377 B.C.) believed that the uterus had a number of cavities, allowing only one gestation within each cavity, which was lined with "tentacles" or "suckers". Leonardo Da Vinci (14521519) and his famous sketches revealed the uterus to contain only one cavity [6].

Vaginal hysterectomy operation performed by Langenbeck (1813) and John Collins Warren (1829) was unsuccessful, while Fenger (1881) described the modern operation of vaginal hysterectomy. Amussat (1840) performed the first recorded myomectomy and Dr. Walter Burnham (1853) successfully removed a leiomyomatous uterus [7].

Max Brodel's illustration of Richardson's technique of total abdominal hysterectomy helped turn the tide in favour of total, rather than subtotal hysterectomy [7].

Study conducted by Modupoela S et al (2009) on hysterectomy specimens over a period of ten years concluded that the clinical indication for hysterectomy and histopathological outcome were comparable in over $90 \%$ of cases [8].
Gupta $\mathrm{G}$ et al (2010), in their two years study stated that, $96 \%$ of hysterectomies were done for benign indications and the most common pathology identified was leiomyoma followed by adenomyosis, endometrial hyperplasia, endometrial polyp [4].

In a descriptive study of 100 hysterectomy specimens conducted by Sarfraz R et al (2011), most common neoplastic lesions were leiomyoma, adenomyosis, endometrial hyperplasia, etc and some of the specimens had more than one lesion in the body of uterus and concluded that coexistence of adenomyosis and leiomyoma were common [2].

Hysterectomy is the most commonly performed surgery in gynaecological practice. It provides definitive cure and accurate diagnosis. In present study, total abdominal hysterectomy with or without bilateral salpingooophorectomy (84\%) was the commonest which correlated with studies conducted by Modupeola $\mathrm{S}$ et al (90.9\%) [8], Huma ZE et al (81.2\%) [9] and Patil HA et al (68.6\%) [10]. The peak age incidence of hysterectomy cases in this study was in 41-50 years age group (45.33\%) which correlated with studies done by Gupta G et al (51.40\%) [4], Khaniki M et al (40\%) [11] and Rather 
GR et al (47.27\%) [5]. The present study showed a mean age of 42.15 years which almost corroborated with the study of Kaur SJ et al [12] where the mean age was 46 years.

In the present study the most common clinical indication for hysterectomy was fibroid uterus $(45.55 \%)$ which was comparable to that found by Sachin A et al (48.56\%) [13], Jaleel R et al (40.4\%) [14] and Kaur SJ et al (57\%) [12].

The most common histopathological diagnosis was leiomyoma (267 cases; 59.33\%) followed by adenomyosis (135 cases; 30\%) and malignancy included adenocarcinoma of endometrium (12 cases; 2.67\%), MMMT (2 case; $0.44 \%$ ), low grade leiomyosarcoma (2 case; $0.44 \%$ ) and a rare case of bicornuate uterus ( 1 case; $0.22 \%$ ) which almost correlated with studies of Ranabhat SK et al [3], Gupta G et al [4], Pity IS et al [15] and Chaturvedi $\mathrm{V}$ et al [16] and Kaur SJ et al [12]. A rare and interesting case $(0.22 \%)$ of bicornuate uterus with intramural leiomyoma was noted in this study, which correlated with study of Eligar RC et al [17].

Variants of leiomyoma were seen in 9 cases $(3.37 \%)$ of which 8 cases $(88.8 \%)$ were of cellular leiomyoma and a case $(11.1 \%)$ of symplastic leiomyoma. This corroborated well with study of Manjula K et al [18]. Of the 267 cases of leiomyoma, 37 cases $(13.85 \%)$ showed degenerative changes such as hyaline change ( 29 cases; $78.37 \%$ ), cystic degeneration, calcification and red degeneration, among which hyaline change was most common. Similar findings were noted in the study of Persaud V et al [19], where hyaline change accounted to 172 cases $(63 \%)$.

In the present study 207 cases of $450(46 \%)$ had cinicopathological correlation. Similar findings were noted by Gupta G et al (46.4\%) [4]. Out of total number of cases $(46 \%)$ which had cinicopathological correlation, majority of them belonged to malignant lesions $(87.5 \%)$ and leiomyoma (65.16\%). Similar findings were seen in study by Jaleel R et al [14].

According to study done by Jandial $\mathrm{R}$ et al, a few incidental findings and multiple pathologies can be missed clinically so a proper clinicopathological correlation of uterine lesions is necessary for further treatment and follow up of the cases [20].

\section{Conclusion}

Hysterectomy still remains the widely used treatment modality for varied uterine pathologies in developing as well as developed countries. Every hysterectomy
Original Research Article

specimen should be subjected to histopathological examination to correlate the spectrum of clinical versus histopathological diagnosis. There is a further scope for more research on this study giving due importance to clinical diagnosis and have a better correlation with histopathological diagnosis, inorder to reduce the morbidity and mortality, document rare and incidental lesions and add to the plethora of lesions, already described.

\section{What the study adds to the existing knowledge?}

The present study provides a fair insight into the histological patterns of lesions in hysterectomy specimens at our institution. Though the histopathological analysis correlates with the clinical diagnoses, one should bear in mind about few lesions, which can also occur as pure incidental findings.

\section{Author's contribution}

Dr. Tejeshwini Patil, Dr. Madhavi Kulkarni and Dr. A S Anand - Study concept, designing the study, acquisition, analysis and interpretation of data, compiled literature sources and drafting the manuscript.

Dr Kajal B Punyashetty- Compiled literature sources and Checked References.

Findings: Nil; Conflict of Interest: None initiated Permission from IRB: Yes

\section{References}

1. Prat J, Female reproductive system. In: Damjanov I and Linder J. Anderson's Pathology, 10 ${ }^{\text {th }}$ ed, MosbyYear Book, 1996;2:2261-2275.

2. Sarfraz R, Ahmed MM, Tahir TM, Ahmed MS. Benign Lesions in Abdominal Hysterectomies in Women Presenting with Menorrhagia. Biomedical. 2011; 27:7275.

3. Ranabhat SK, Shrestha R, Tiwari M, Sinha DP, Subedee LR. A retrospective histopathological study of hysterectomy with or without Salpingo-ophorectomy specimens. JCMC 2010;1(1):26-29.

4. Gupta G, Kotasthane DS, Kotasthane VD. Hysterectomy: A clinico-pathological correlation of 500 Cases. The Int J Gynaecol Obstet. 2010;14(1).

5.Rather GR, Gupta Y, Bardhwaj S. Patterns of Lesions in Hysterectomy Specimens: A Prospective Study. JK Sci. 2013;15(2):63-68. 
Original Research Article

6. Gershenson DM, Decherny AH and Curey SL. 'Uterine surgery' in Operative Gynaecology. WB Saunders Company, U.S.A. 1993; 353-54.

7. Thompson JD and Rock JA. Telinde's Operative Gynecology. J.B. Lippincott Company, Philadelphia, Pennsylvania. 10th ed Chapters 1, 13 and 27. 2008; 1-10, 297-99, 663-68.

8. Modupeola S, Adesiyun, Agunbiade and Duro M. Clinicopathological assessment of Hysterectomies in Zaria. Eur J Gen Med.2009;6(3):150-153. doi: 10. $29333 /$ ejgm $/ 82660$

9. Huma ZE, Naeem A, Shoaib M, Fayyaz S, Arjumand. A Clinicopathological Review of Elective Hysterectomies in Sir Ganga Ram Hospital. Pak J Med Health Sci.2012:6(4):970-972.

10. Patil AH, Patil A and Mahajan SV. Histopathological Findings in Uterus and Cervix of Hysterectomy Specimens. MVP J Med Sci. 2015;2(1):26-29.

11. Khaniki M, Shojaie M, Tarafdari AM. Histopathological study of hysterectomy operations in a university clinic in Tehran from 2005 to 2009. J Fam Reproduct Health 2011;5(2):51-55.

12. Kaur SJ, Gupta RK, Kaur M. Clinicopathological Study of Uterine Lesions in Hysterectomy Specimens. Ann Int Med Dent Res 2018;4(1):18-22.

13. Sachin AK, Mettler L, and Jonat W. Operative spectrum of hysterectomy in a German university hospital. J Obstet Gynecol India. 2006;56(1):59-63.
14. Jaleel R, Khan A, Soomro N. Clinico-pathological study of abdominal hysterectomies. Pak J Med Sci. 2009; 25(4):630-634.

15. Pity IS, Jalal AJ, Hassawi BA. Hysterectomy: A Clinicopathologic Study. Tikrit Med J. 2011; 17 (2): 716

16. Chaturvedi V, Dayal S, Srivastava D, Gupta V, Chandra A. Pattern and frequency of uterine pathologies among hysterectomy specimens in rural part of northern India: a retrospective secondary data analysis. Ind $\mathrm{J}$ Commun Health. 2014;26(1):103-106.

17. Eligar RC, Choukimath SM. Bicornuate [bicornis, unicollis] uterus, a congenital malformation associated with pathological lesions: a clinicopathological study of 4 rare cases. J of Evolution of Med and Dent Sci. 2014;4(3): 4608-4614. doi: 10.14260/jemds/2014/2484

18. Manjula K, Rao KS, Chandrashekhar HR. Variants of Leiomyoma: Histomorphological Study of Tumors of Myometrium. J South Asian Fed Obstet Gynaecol. 2011; 3(2):89-92.

19. Persaud VJ and Arjoon PD. Uterine Leiomyoma, Incidence of degenerative changes and a correlation of associated symptoms. Obstet Gynaecol. 1970;35(3): 432-436.

20. Jandial R, Choudhary M, Singh K. Histopathological analysis of hysterectomy specimens in a tertiary care centre: Study of 160 cases. Int Surg J. 2019;6(8): 2856-2859. doi: http://dx.doi.org/10.18203/2349-2902. isj 20193330

\section{How to cite this article?}

Patil T, Kulkarni M.A, Anand A.S, Punyashetty K.B. Histomorphological study of lesions of corpus uteri in hysterectomy specimens: a tertiary care centre study. Trop J Path Micro 2019;5(9):684-691.doi:10.17511/jopm.2019.i09.11. 